\title{
Testing physiologically-based resource allocation rules in laboratory experiments with Daphnia magna Straus.
}

\author{
A.J.A. Nogueira ${ }^{1 *}$, D.J. Baird ${ }^{2}$, A.M.V.M. Soares ${ }^{1}$ \\ ${ }^{1}$ CESAM, Departamento de Biologia, Universidade de Aveiro, Campus Universitario de Santiago, 3810-193 Aveiro, Portugal. \\ 2 NWRI / Environment Canada \& Canadian Rivers Institute, Department of Biology University of New Brunswick, 10 Bailey Drive, P.O. Box \\ 45111, Fredericton, New Brunswick, Canada, E3B 6E1.
}

\begin{abstract}
The rules governing the allocation of available resources to varying physiological processes are evaluated in three physiologically-based models of individual Daphnia. In laboratory experiments using a single clone, subjected to varying regimes of food deprivation, growth was found to vary inversely with food level, ceasing in the absence of food, implying that growth allocation is derived directly from food. Reproductive investment was reduced under food deprivation, ceasing at low food levels. By exposing juvenile and adult daphnia to varying food deprivation regimens during different periods within their intermoult interval, it was shown that instar durations vary as a function of body size and food availability independent of the age of the animal. For the first time, the role of variable instar duration, which critically influences physiological processes such as growth, moulting and reproduction in adult females, that has been neglected by existing Daphnia models, is explicitly incorporated in a physiological allocation model. The consequent model provides a simplified framework for modelling the consequences of food deprivation in cladocerans which has important application in population modelling and environmental risk assessment.
\end{abstract}

Keywords : Daphnia magna, resource allocation, physiologically-based models, food resources.

\section{Introduction}

Physiological models of individual organisms describe the mechanisms by which organisms acquire and allocate resources to meet the demands of the competing physiological processes underlying growth, reproduction and survival. Moreover, they are also concerned with how these processes are governed by body size and maturation state in a varying environment. Such models are constructed for a variety of purposes, including testing of life-history theory (e.g. Bradley et al. 1991b) and the construction of higher-order ecological models at population (e.g. Gurney et al. 1990) or community level (e.g. Hommen et al. 1993). Daphnia is a genus of freshwater cladoceran widely used in ecological and toxicological experimentation (De Bernardi \& Peters 1987). For this reason, several physiologically-based allocation models of Daphnia have been constructed as models of individuals (e.g. Gurney et al.

\footnotetext{
* Corresponding author :

E-mail : anogueira@bio.ua.pt
}

1990, Hallam et al. 1990, Kooijman 1994). These various allocation models are based on sets of rules that determine the partitioning of available resources between competing physiological processes. These rules explicitly assume either (a) that animals have fixed allocation priorities throughout their life cycle, or (b) that there is an instantaneous and irreversible shift in allocation priorities as juveniles achieve maturity. While these simplifying assumptions have been made for the convenience of using outputs in higher-order models, they may not correctly predict specific phenomena of interest (e.g. timing and quantity of growth, reproduction) under varying food conditions. Life-history theory predicts that resource allocation priorities should change dynamically with changing environmental circumstances during an animal's life cycle (Delaguerie et al. 1993, Hairston \& Bohonak 1998, Stearns 2000), and thus fixed allocation models do not seem to be compatible with this assertion. Arguably, even when assuming a simple binary life-history of juvenile and adult stages, it still seems likely that allocation priorities will be a dynamic function of environmental conditions, nutritional status and maturation 
status, as has been suggested in previous experimental studies (Enserink et al. 1995).

A more realistic approach thus assumes that resource allocation priorities change gradually and continuously over the life cycle, rather than instantaneously, as assumed in existing modelling approaches (e.g. Gurney et al. 1990, Hallam et al. 1990). The 'gradualshift' approach is more realistic, since we know that mass allocation in animals (e.g. the provisioning of eggs) is a dynamic process, with trade-offs between growth, reproduction and survival occurring in mature individuals (Enserink et al. 1995).

Some Daphnia models have sought to generalise to a variety of environmental situations (e.g. Gurney et al. 1990, Hallam et al. 1990, Kooijman 1994) in order to predict parameters required for population modelling. In these cases, however, simplifying assumptions that are biologically incorrect were used, such as fixed instar duration. Porcella et al. (1969) clearly demonstrate variable instar duration in Daphnia. It would be unfair to criticise these models for their inability to capture all aspects of realism in terms of life-cycle phenomena, since this was not their objective. However, it could be hypothesised that this is a consequence of allocation rules being derived to describe specific experimental observations, rather than vice versa. Generalised allocation models should explain the individual performance of animals which is directly related to their nutritional status, under a variable set of environmental conditions.

Environmental conditions that influence the nutritional status of individuals include: temperature (e.g. Lampert 1977), food availability (e.g. Lampert 1987), and the presence of toxic substances, e.g. pesticides (Fernandez-Casalderrey et al. 1994, Kersting \& Van Der Honing 1981) and metals (Allen et al. 1995, Gulati et al. 1988). Ingestion rates are a function of previously mentioned environmental conditions. Reduced ingestion rates can be easily simulated through controlled food deprivation, thus manipulation of food conditions is probably the best way of testing existing allocation strategies. Also, in describing resource allocation in crustaceans, such as Daphnia, it is essential to consider the pivotal role of the moulting process. Direct observation of individuals showed that immediately prior to moulting, individuals are mobilising stored reserves for allocation to three key processes:

1. growth, in which the animal is allocating mass to form the new carapace, which will result in the animal increasing in length after shedding the old carapace (Peters \& De Bernardi 1987);
2. reproduction, since the animal must shed its carapace to allow the eggs to pass from the ovary into the brood pouch (Peters \& De Bernardi 1987);

3. survival, since the animal will die if it fails to moult successfully, as a result of fouling of the old carapace (pers. obs.), which would impair carapace permeability, and thus interfere with ion and gas exchange.

The life cycle of Daphnia can be separated into a juvenile phase, where the animal is not reproducing, and an adult phase where the animal is capable of allocating resources to eggs. Figure 1 represents the life cycle of Daphnia magna Straus as a series of juvenile and adult instars, designated $\mathrm{J}_{\mathrm{n}}$ and $\mathrm{A}_{\mathrm{n}}$ respectively. This figure also indicates the sequence of reproductive events occurring within an instar as: first, allocation of resource to the eggs, followed by shedding of the carapace and release of neonates from the brood pouch, and finally in the deposition of newly-formed eggs into the brood pouch (Bradley et al. 1991a, Zaffagnini 1987). Thus, the timing of reproductive events is directly determined by the timing of moulting. Since the evolutionary performance of an individual is determined by its contribution to population growth, it is critical to correctly describe the moult process. The terminology employed in Fig. 1 will be used throughout the rest of the paper to describe life-cycle stages.

Existing physiological allocation models for Daphnia (Table 1) differ markedly in their approach to the following key allocation rules:

- Instar duration (rule A) - instar duration in cladocerans determines other physiological processes (e.g. increase in length, shedding of the carapace, release of eggs in adults).

- Resource partitioning (rule B) - describes the relative investment between different physiological processes (e.g. growth, reproduction, metabolism), that can be in fixed proportions (static) or adaptive (variable proportions).

- Allocation to growth (rule C) - considers the source (i.e. directly from assimilate or from stored reserves) used to irreversibly increase structural mass (where structural mass is defined as the fraction to total body mass which cannot be used for metabolic purposes). Thus, this rule together with rule $\mathrm{B}$ describes the source and proportion of resources allocated to growth. This is crucial, since it determines under which conditions the individual can grow.

- Allocation to reproduction (rule D) - considers the source of allocation of materials for egg production (i.e. whether from assimilate or stored reserves). The 


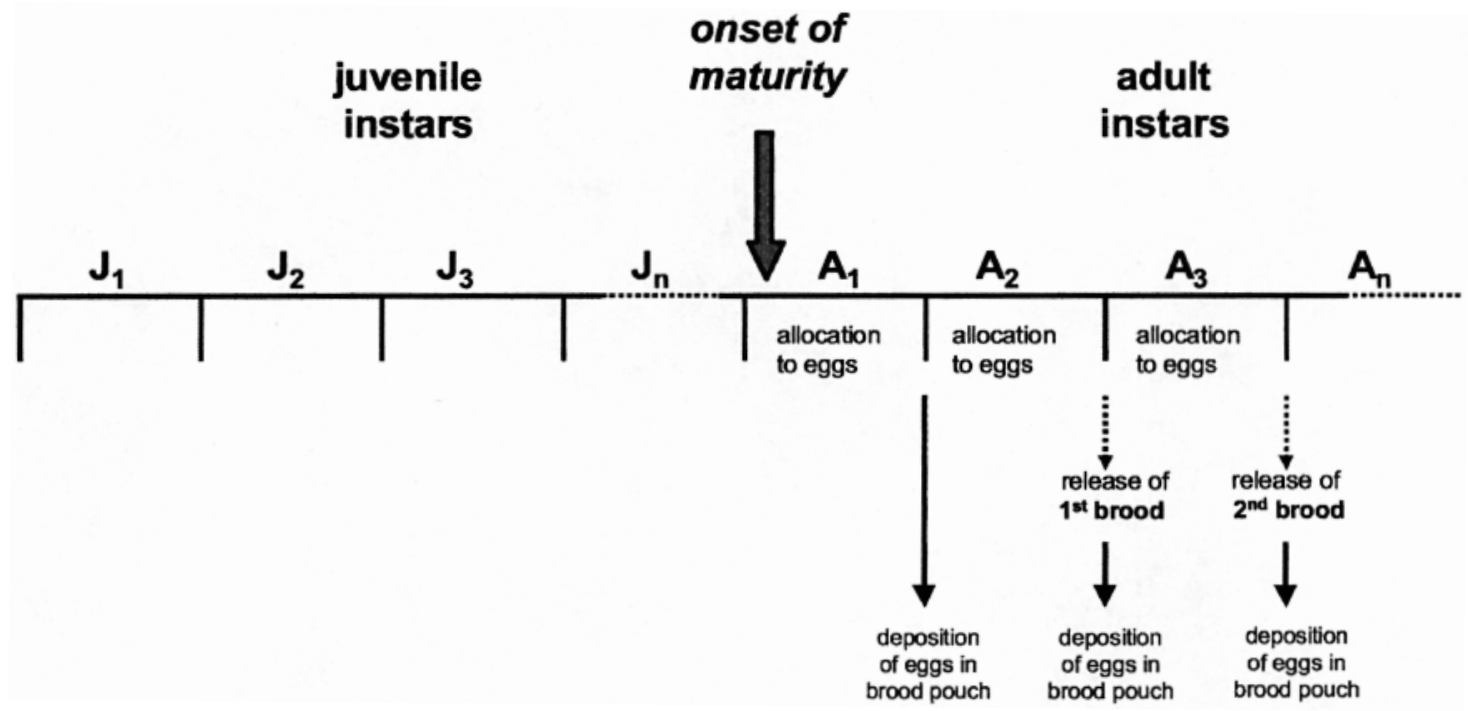

Fig. 1. Description of the life cycle of D. magna as a series of juvenile non-reproductive instars $\left(\mathrm{J}_{1} \ldots \mathrm{J}_{\mathrm{n}}\right)$ and adult reproductive instars $\left(A_{1} \ldots A_{n}\right)$, including a representation of the sequence of reproductive events that take place before and after moulting (see text for further explanation).

Table 1. Allocation assumption from models tested in this study. (n.a. - not applicable).

\begin{tabular}{|c|c|c|c|c|}
\hline \multicolumn{2}{|r|}{ Allocation rule } & $\begin{array}{c}\text { Gurney et al. } \\
1990\end{array}$ & Kooijman 1994 & $\begin{array}{c}\text { Hallam et al. } \\
1990\end{array}$ \\
\hline $\mathbf{A}$ & instar duration & fixed & n.a. & fixed \\
\hline $\mathbf{B}$ & $\begin{array}{l}\text { partition of } \\
\text { resources }\end{array}$ & adaptive & static & static \\
\hline $\mathbf{C}$ & $\begin{array}{l}\text { allocation to } \\
\text { growth }\end{array}$ & from assimilate & from reserves & from assimilate \\
\hline $\mathbf{D}$ & $\begin{array}{l}\text { allocation to } \\
\text { reproduction }\end{array}$ & $\begin{array}{c}\text { continuously and } \\
\text { irreversibly from } \\
\text { assimilate }\end{array}$ & $\begin{array}{c}\text { continuously and } \\
\text { irreversibly from } \\
\text { reserves }\end{array}$ & $\begin{array}{c}\text { end of the instar } \\
\text { using available } \\
\text { reserves }\end{array}$ \\
\hline $\mathbf{E}$ & $\begin{array}{l}\text { allocation to } \\
\text { metabolism }\end{array}$ & $\begin{array}{l}\text { continuously and } \\
\text { irreversibly from } \\
\text { assimilate or } \\
\text { reserves }\end{array}$ & $\begin{array}{l}\text { continuously and } \\
\text { irreversibly from } \\
\text { reserves }\end{array}$ & $\begin{array}{l}\text { continuously and } \\
\text { irreversibly from } \\
\text { reserves }\end{array}$ \\
\hline $\mathbf{F}$ & $\begin{array}{l}\text { allocation to } \\
\text { carapace }\end{array}$ & $\begin{array}{l}\text { continuously and } \\
\text { irreversibly from } \\
\text { assimilate }\end{array}$ & $\begin{array}{l}\text { included in } \\
\text { metabolism }\end{array}$ & $\begin{array}{l}\text { end of the instar } \\
\text { from reserves }\end{array}$ \\
\hline $\mathbf{G}$ & $\begin{array}{c}\text { recovery from } \\
\text { starvation }\end{array}$ & $\begin{array}{c}\text { reserves have } \\
\text { absolute priority }\end{array}$ & $\begin{array}{l}\text { reproduction has } \\
\text { priority }\end{array}$ & $\begin{array}{l}\text { no process has } \\
\text { priority }\end{array}$ \\
\hline
\end{tabular}

process of allocation of mass to eggs can be considered both continuous and irreversible or a discrete process. This rule together with rule $\mathrm{B}$ describes the source and proportion of available resources allocated to reproduction.
- Allocation to metabolism (rule E) - considers the source of mass used to meet metabolic costs (i.e. the source of materials for all energy-demanding processes like cell maintenance and activity).

- Allocation to the carapace (rule F) - considers the 
source of mass used to meet moulting costs (i.e. the formation of a new carapace).

- Recovery from food deprivation (rule G) - An animal's ability to recover following periods of food deprivation is dependent on a stored reserves pool from which the individual can derive materials to meet metabolic costs. This rule concerns the trade-offs between growth, reproduction and/or stored reserves when food conditions improve after a stressful period.

In this paper, existing physiological allocation models for Daphnia are tested, in order to derive a generalised allocation model of an individual that can be used to predict growth and reproduction of Daphnia under stress. Food shortage is a common stress factor in populations in the wild (e.g. Lampert 1987) and in the laboratory conditions in standard laboratory bioassays in this organism (Allen et al. 1995). Given that existing models differ in the approach used it is necessary to test them using a simple form of environmental stress. Since food stress is easily imposed and controlled, it will be used to evaluate the allocation models and test the following hypotheses directly associated with the previously stated allocation rules:

I) Instar duration will vary proportionally with body length, assuming that larger individuals take longer to moult;

II) Instar duration will increase in proportion to the duration of the food deprivation period, assuming that under shortage of food resources moulting is delayed;

III) Growth in length will be reduced in proportion to the duration of the food deprivation period, assuming that under shortage of food resources growth is reduced;

IV) Individuals reach maturation are mature when they reach a minimum body length and start producing eggs;

V) Adults will reduce clutch size proportionally to the duration of the period of food deprivation, if under shortage of food resources clutch size is reduced.

\section{Materials and methods}

\section{Culture system}

\section{Algal culture}

A large-scale semi-continuous culture of the freshwater unicellular alga Chlorella vulgaris Beijerinck was established in 10 litre fermenters, each containing 6 litres of Woods Hole MBL. The cultures were maintained at $20 \pm 2{ }^{\circ} \mathrm{C}$, under continuous light conditions (2000 lux). The media was aerated with clean air using an air pump (Maxima 4W, Weltweit, Germany) at a rate of $2-4$ litres of air per minute. Algal cultures were harvested every other day in exponential phase to ensure a food supply of consistent quality.

\section{Cladoceran cultures}

Individuals of a single clone of the cladoceran Daphnia magna Straus (clone F sensu Baird et al. 1991) were maintained using individual cultures and long-term bulk cultures. Individual cultures of the Daphnia clone were maintained in $150 \mathrm{~mL}$ screw top glass jars containing $100 \mathrm{~mL}$ of enriched ASTM hardwater, with the addition of a standard organic extract (Baird et al. 1989). Animals were transferred to clean medium and fed daily with $6.5 \times 10^{5}$ cells $\mathrm{mL}^{-1}$ Chlorella vulgaris Beijerinck, corresponding to $3 \mathrm{mg} \mathrm{C} \mathrm{L}^{-1}$ or $7.5 \mathrm{mg} \mathrm{DW}$ $\left.\mathrm{L}^{-1}\right)$. Photoperiod was set to a $14 \mathrm{~h}$ light: $10 \mathrm{~h}$ dark cycle and temperature at $20 \pm 0.5^{\circ} \mathrm{C}$. Bulk cultures of 10 individuals : three adult females with eggs present in the brood pouch, four adolescents, and four neonates were maintained in $1000 \mathrm{~mL}$ glass covered beakers containing $800 \mathrm{~mL}$ of medium. Culture medium and photoperiod were identical to those of individual cultures. The medium was completely replaced every 15 days and the culture restarted with the same age structure. These conditions are known to prevent the occurrence of males and ephippia, thus ensuring continuous supply of parthenogenetically produced offspring (Banta \& Brown 1929, Berge 1978, Carvalho \& Hughes 1983, Doma 1979, Slobodkin 1954, Stross \& Hill 1965).

\section{Experimental design}

Pulsed food-deprivation experiments (Bradley et al. 1991a), where groups of individuals are exposed to short periods of food deprivation during part or all of a specific instar, were conducted using juvenile $\left(\mathrm{J}_{3}\right)$ and adult stages $\left(\mathrm{A}_{2}\right)$ of $D$. magna maintained at high food levels (7.5 mg DW L $\mathrm{m}^{-1}$ of algal cells), to assess allocation responses within these two life cycle stages. All animals were maintained and monitored as individuals every $3 \mathrm{~h}$, for the duration of the experiment, to obtain precise estimates of instar duration.

Experiment 1: Effects of pulsed food deprivation on juveniles (instar $\mathrm{J}_{3}$ )

Female juveniles $(n=600)$ released from the maternal brood pouch within $3 \mathrm{~h}$ of each other were randomly assigned to the following three treatments when entering the instar J3: A) without food deprivation $(\mathrm{n}=275)$; B) $18 \mathrm{~h}$ food deprivation $(\mathrm{n}=200)$; and C) whole instar food deprivation $(n=125)$. Six random samples of 75 individuals were taken from: i) group A, at the end of $\mathrm{J}_{2}$, after $18 \mathrm{~h}$ on $\mathrm{J} 3$, and at the end of $\mathrm{J} 3$; ii) group $\mathrm{B}$ after $18 \mathrm{~h}$ on $\mathrm{J} 3$, and at the end of $\mathrm{J} 3$; and, 
iii) group $\mathrm{C}$ at the end of $\mathrm{J}_{3}$. The remaining individuals (50 per group) were followed until they attained instar $\mathrm{A}_{2}$.

Experiment 2 : Effects of pulsed food deprivation on adults

Females $(n=620)$ released from the maternal brood pouch within $3 \mathrm{~h}$ of each other were cultured individually. These females were randomly assigned to four treatments when entering instar $\left.A_{2}: A\right)$ without food deprivation $(\mathrm{n}=170)$; B) $24 \mathrm{~h}$ food deprivation $(\mathrm{n}=170)$; C) $48 \mathrm{~h}$ food deprivation $(\mathrm{n}=175)$; D) wholeinstar food deprivation $(n=105)$. Random samples of individuals were taken at the end of instar $\mathrm{A}_{2}$ (70 individuals from group $A), A_{3}$ (70 individuals from group A, 90 individuals from group $B, 80$ individuals from group $C$, and 45 individuals from group $\mathrm{D})$, and $\mathrm{A}_{4}(35$ individuals from group $\mathrm{B}, 40$ individuals from group $\mathrm{C}$, and 20 individuals from group D).

\section{Measurement of life-history traits}

Body length in Daphnia is usually measured as the distance between the anterior most point of the head and the base of the spine. Since this procedure requires manipulation of animals and is potentially harmful, an indirect method based on the relationship between the length of the first exopodite of the second antennae and the body length of an individual was used. The relationship between body length (BL) and antennae length (AL) was determined independently, before conducting the experiments, in a random group of individuals ranging from small newborns to large adults (4.03 $\mathrm{mm}$ long) as :

$$
\mathrm{BL}=-0.59+1.09 \times \mathrm{AL}, \mathrm{r}^{2}=0.964, \mathrm{n}=75, \mathrm{p}<0.0001
$$

Body length was determined indirectly for each instar, in random groups of approximately 80 individuals for each experimental treatment, using the length of the first exopodite of the second antennae measured in the carapace released at the end of each instar. Body length from live individuals sampled during the experiments, was measured directly and egg-bearing females were debrooded (Glazier 1991) and the eggs counted.

\section{Statistical Methods}

Statistical analysis was performed using the SigmaStat 2.03 package (SPSS 1987) using standard methodology (Zar 1998). Non-linear regression analysis was used to establish the relationships between body length and other biological parameters (i.e. instar duration, fecundity), and between age and body length. Linear models, based on least-squares regression, were established for each experiment (i.e. food deprivation in juvenile instars and food deprivation in adult instars) to describe the effects of the duration of the period of food deprivation on instar duration and individual growth (i.e. the increase in body length). The degree of association between the regressed variables was judged using the coefficient of determination $\left(\mathrm{r}^{2}\right)$ and the respective probability level. Analysis of covariance between linear regression models was performed as outlined in Zar (1998).

\section{Results}

\section{Instar duration vs body length relationship}

In contrast to previous assumptions, instar duration in D. magna was found to be variable, and was exponentially related to body length at the start of the instar (Fig. 2), scaling approximately with surface area $(\boldsymbol{b}=$ $\left.1.764, \mathrm{r}^{2}=0.746, \mathrm{n}=796, \mathrm{p}<0.0001\right)$.

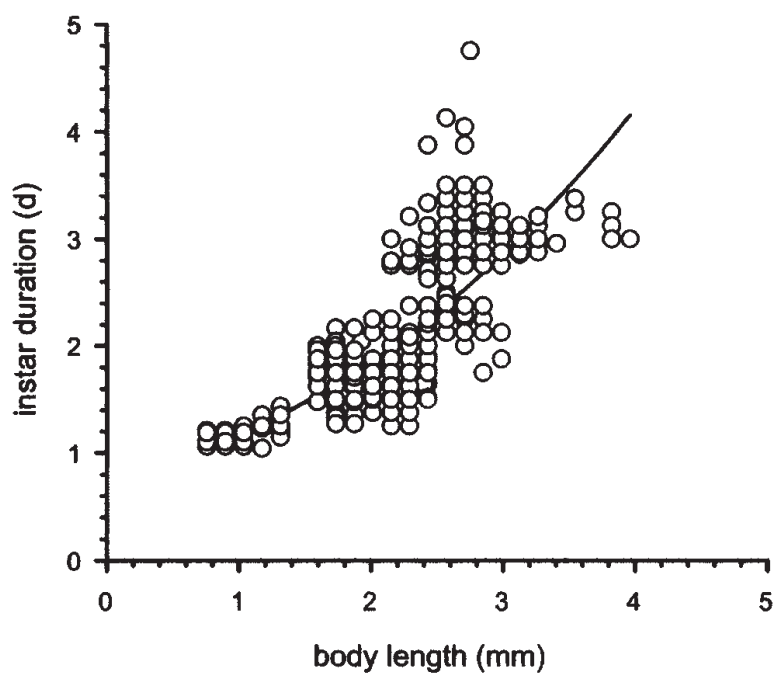

Fig. 2. Relationship between instar duration and body length in $D$. magna $\left(\right.$ duration $=0.898+0.282 \times$ length $^{1.764}, \mathrm{r}^{2}=0.746, \mathrm{n}=$ 796, $\mathrm{p}<0.0001)$.

\section{Instar duration vs duration of food deprivation period}

Instar duration (Inst) increased proportionally with increasing duration of food deprivation (Dep) in both juveniles $\left(\right.$ Inst $=1.653+0.229 \times D e p, \mathrm{r}^{2}=0.449$, $\mathrm{n}=358, \mathrm{p}<0.001)$ and adults (Inst $=3.150+0.243 \mathrm{x}$ 
Dep, $\left.\mathrm{r}^{2}=0.459, \mathrm{n}=301, \mathrm{p}<0.001\right)$. Moreover, the duration of food deprivation elicited a similar response in both juveniles and adults, since a comparison of the two slopes indicated that they did not differ significantly $(t=-0.604, \mathrm{df}=655, \mathrm{p}=0.546)$ and thus a common slope of 0.24 was computed. Thus, the effect of varying durations of food deprivation was independent of the maturation stage of an individual.

\section{iod \\ Body length vs duration of food deprivation per-}

Growth between instars, expressed as body length $(B L)$, varied inversely with the duration of the period of food deprivation during an instar. Moreover, the duration of the period of food deprivation (Dep) again produced a similar pattern in both juveniles $(B L=$ $2.110-0.063 \times$ Dep, $\left.\mathrm{r}^{2}=0.055, \mathrm{n}=316, \mathrm{p}<0.001\right)$ and adults $\left(B L=3.024-0.065 \times\right.$ Dep, $\mathrm{r}^{2}=0.138, \mathrm{n}=174$, $\mathrm{p}<0.001)$. A comparison of the slopes for the two groups (Table 2) indicated again that they did not differ significantly $(t=0.12, d f=490, p=0.904)$. Growth in length was reduced under increasing duration of food deprivation, and ceased (i.e. moulting occurred without growth increment) when food was absent for the entire instar in both juveniles $\left(\mathrm{J}_{3}: \mathrm{t}=-1.534, \mathrm{df}=79\right.$, $\mathrm{p}>0.05)$ and adults $\left(\mathrm{A}_{2}: \mathrm{t}=-1.829, \mathrm{df}=76, \mathrm{p}>0.05\right)$.

Table 2. ANCOVA of the relationships between (1) the duration of the food deprivation period and instar duration, and (2) the duration of the food deprivation period and body length for individuals in instars $J_{3}$ and $\mathrm{A}_{2}$. (* - significant differences).

\begin{tabular}{|c|c|c|c|c|c|c|}
\hline Endpoint & $\begin{array}{c}\text { Regression } \\
\text { parameter }\end{array}$ & & $\begin{array}{l}\text { meter } \\
\text { lue }\end{array}$ & $\mathbf{F}$ & $\mathrm{df}$ & p \\
\hline \multirow{4}{*}{ (1) Instar duration } & \multirow{2}{*}{ Slopes } & $J_{3}$ & 0.229 & \multirow{2}{*}{0.365} & \multirow{2}{*}{1,655} & \multirow{2}{*}{0.545} \\
\hline & & $\mathbf{\mathbf { A } _ { 2 }}$ & 0.243 & & & \\
\hline & \multirow{2}{*}{ Intercepts * } & $\mathbf{J}_{\mathbf{3}}$ & 1.653 & \multirow{2}{*}{3657.123} & \multirow{2}{*}{1,656} & \multirow{2}{*}{$<0.001$} \\
\hline & & $\mathbf{A}_{2}$ & 3.150 & & & \\
\hline \multirow{4}{*}{ (2) Body length } & \multirow{2}{*}{ Slopes } & $\mathbf{J}_{3}$ & -0.063 & \multirow{2}{*}{0.014} & \multirow{2}{*}{1,490} & \multirow{2}{*}{0.904} \\
\hline & & $\mathbf{A}_{2}$ & -0.065 & & & \\
\hline & \multirow{2}{*}{ Intercepts * } & $\mathbf{J}_{\mathbf{3}}$ & 2.111 & \multirow{2}{*}{1717.110} & \multirow{2}{*}{1,491} & \multirow{2}{*}{$<0.001$} \\
\hline & & $\mathbf{A}_{2}$ & 3.024 & & & \\
\hline
\end{tabular}

\section{Maturation and body length}

Increasing periods of food deprivation during $\mathrm{J}_{3}$ resulted in older (One-way ANOVA: $\mathrm{F}=13.798, \mathrm{df}=2$, 129, $\mathrm{p}=0.001$; Tukey test: all treatments differed significantly for $\mathrm{p}=0.05)$ and smaller individuals at first brood (One-way ANOVA: $F=13.798$, df=2, 129, $\mathrm{p}=0.001$; Tukey test: controls differed significantly from individuals deprived of food for $\mathrm{p}=0.05$ ). These combined effects (see Fig. 3) were the result of reduced food intake during the instar (18h food deprivation) or delay of maturity for one instar (one instar food deprivation). Under control food conditions, an increase in the number of the instars to reach maturity (4, 5 and 6 instars; see Fig. 4) resulted in older individuals (One-way ANOVA: $\mathrm{F}=6801.004$, df=2, 585, $\mathrm{p}=0.001$; Tukey test: all groups differed significantly for $\mathrm{p}=0.05$ ). Moreover, the increase in the number of instars to reach maturity resulted also in larger indivi- duals (One-way ANOVA: $F=293.670, d f=2,509$, $\mathrm{p}=0.001$; Tukey test: all groups differed significantly for $\mathrm{p}=0.05$ ).

\section{Reproduction during the food deprivation period}

Brood size was a linear function of body length (Fig. 5), within the size-range studied, for individuals kept under constant food conditions. Food deprivation for $18 \mathrm{~h}$ in $\mathrm{J} 3$ did not affect the relationship between body length and brood size (Fig. 6, Table 2) for the first brood. However, after one full instar of food deprivation there was a slight decrease in the size of the first brood. Individuals from the control treatment, reaching maturity in different instars followed the same trend (Fig. 7, Table 2) resulting in larger first broods being produced by late-maturing, larger individuals. Individuals deprived of food in instar $\mathrm{A}_{2}$ showed a pronounced reduction in brood size, in terms of a de- 


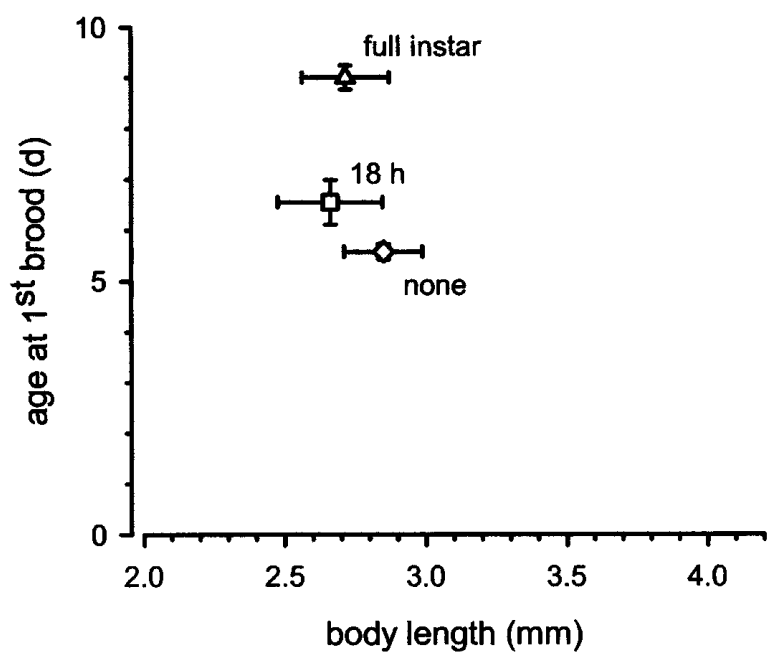

Fig. 3. Age at $1^{\text {st }}$ brood of (a) females deprived of food for different periods (full instar, $18 \mathrm{~h}$, none) in instar $\mathrm{J} 3$ (vertical and horizontal error bars represent the mean \pm standard deviation).

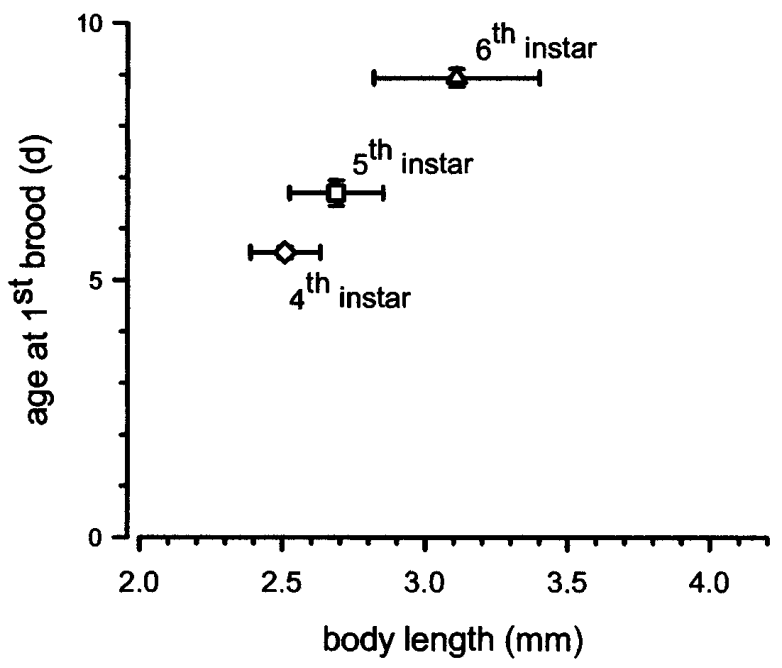

Fig. 4. Age at $1^{\text {st }}$ brood of females reaching maturity at different instars $\left(4^{\text {th }}\right.$ instar, $5^{\text {th }}$ instar, $6^{\text {th }}$ instar). Vertical and horizontal error bars represent the mean \pm standard deviation.

crease in slopes for the relationship between brood size and body length, with increasing food deprivation (Fig. 8). Moreover, reproduction ceased completely when individuals were deprived of food for one instar.

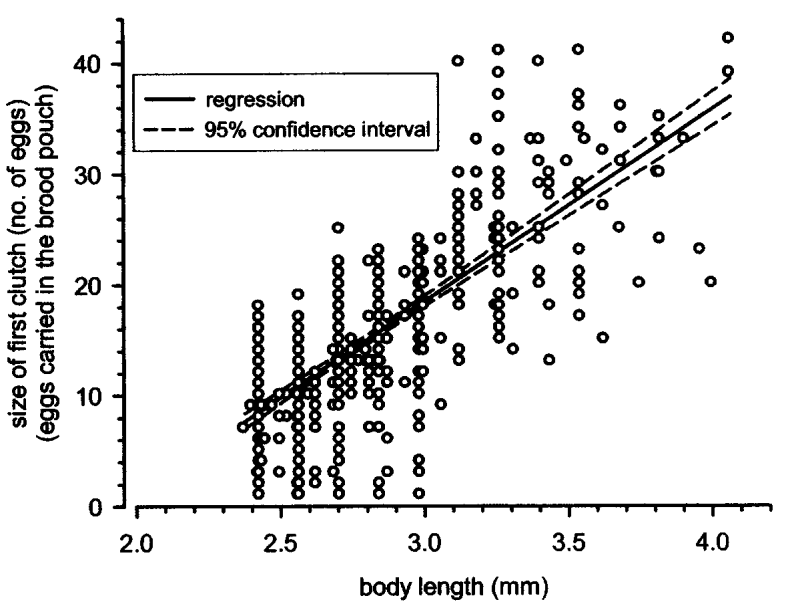

Fig. 5. Relationship between body length and brood size for females in instars $\mathrm{A}_{1}-\mathrm{A}_{4}$, under standard undisturbed conditions (brood = $-33.4+17.3$ ( length, $\mathrm{r}^{2}=0.537, \mathrm{n}=636, \mathrm{p}<0.0001$ ).

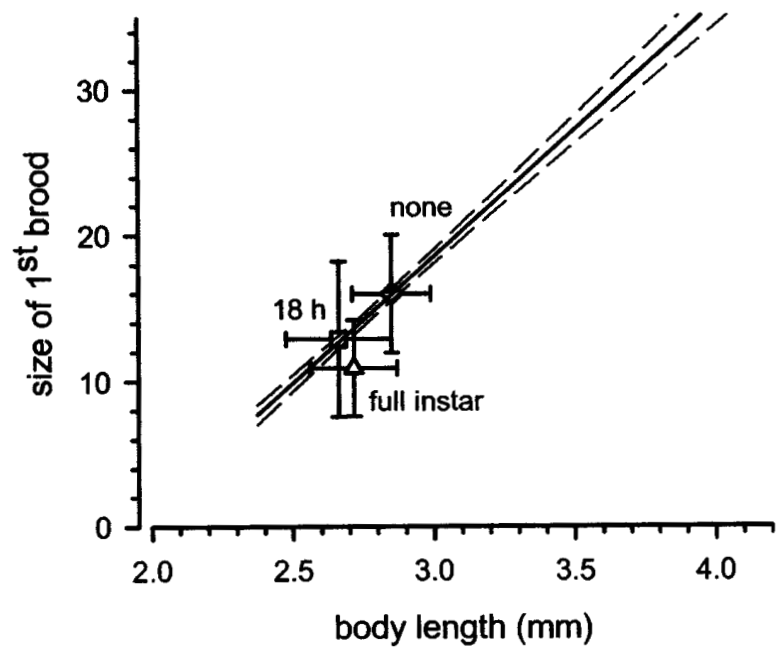

Fig. 6. Size of $1^{\text {st }}$ brood of (a) females deprived of food for different periods in instar J3 (full instar, $18 \mathrm{~h}$, none). Vertical and horizontal error bars represent the mean \pm standard deviation. The lines represent the relationship between body length and brood size (solid line) and the $95 \%$ confidence limit for the regression (dashed lines) for females in instars $\mathrm{A}_{1}-\mathrm{A}_{4}$, under control conditions (see figure 5).

\section{Reproduction under recovery from food depriva-} tion

Exposure to food deprivation during instar $\mathrm{A}_{2}$ extended its effects over instar $\mathrm{A}_{3}$ (Fig. 9, Table 3). Although the slope of the relationship between brood si- 


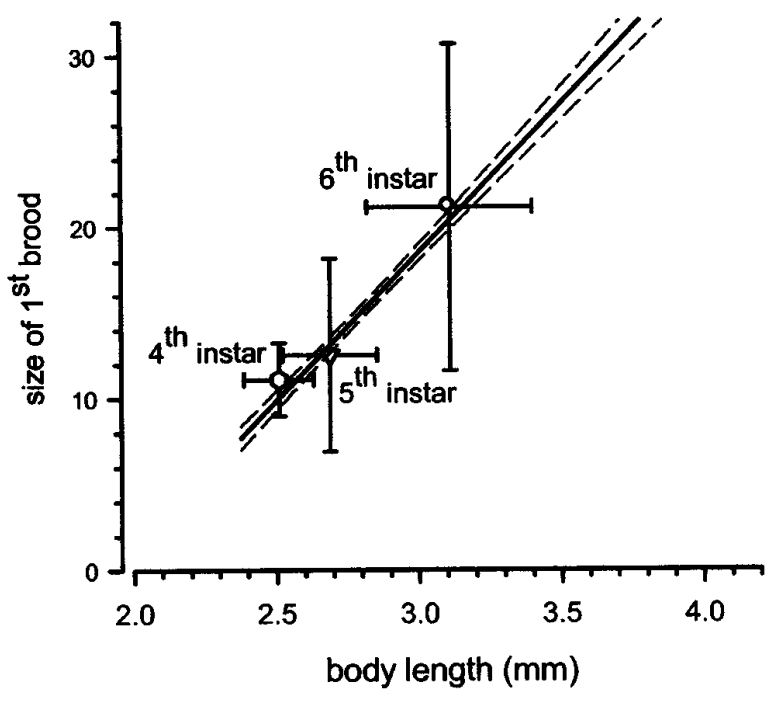

Fig. 7. Size of $1^{\text {st }}$ brood of females reaching maturity at different instars $\left(4^{\text {th }}\right.$ instar, $5^{\text {th }}$ instar, $6^{\text {th }}$ instar). Vertical and horizontal error bars represent the mean \pm standard deviation. The lines represent the relationship between body length and brood size (solid line) and the $95 \%$ confidence limit for the regression (dashed lines) for females in instars $\mathrm{A}_{1}-\mathrm{A}_{4}$, under control conditions (see figure 5).

ze and body length remained constant, the intercepts for the regression lines were significantly different from the control (Table 3). Moreover, regression lines for $24 \mathrm{~h}$ and $48 \mathrm{~h}$ of food deprivation were not statistically different, but the line representing reproduction following a full instar of food deprivation was significantly different from all the others.

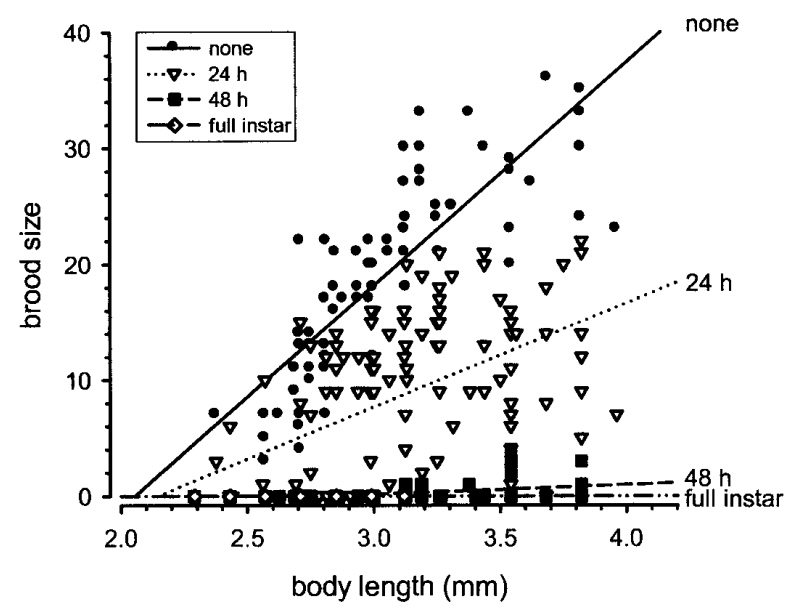

Fig. 8. Relationships between body length and brood size during instar A2 for individuals deprived of food for different periods : none - slope $=19.2\left(\mathrm{r}^{2}=0.643, \mathrm{n}=77, \mathrm{p}<0.0001\right), \mathbf{2 4 h}$ - slope $=$ $9.0\left(\mathrm{r}^{2}=0.247, \mathrm{n}=132, \mathrm{p}<0.0001\right), 48 \mathrm{~h}-$ slope $=0.8\left(\mathrm{r}^{2}=0.185\right.$, $\mathrm{n}=62, \mathrm{p}<0.0001)$, and full instar - slope $=0.0\left(\mathrm{r}^{2}=0.000, \mathrm{n}=\right.$ $37, \mathrm{p}=1.00)$.

\section{Discussion}

None of the existing allocation models for Daphnia can fully explain the results obtained in the experiments described above (Table 4). Treating instar duration as fixed (rule A) is a simplifying assumption used in existing models that is not supported by these observations. Instar duration affects the mass balance of

Table 3 - ANCOVA of the relationships between body length and fecundity for groups of instar $\mathrm{A}_{3}$ individuals during recovery from fixed periods of food deprivation in instar $\mathrm{A}_{2}$ (none, $24 \mathrm{~h}, 48 \mathrm{~h}$, and whole instar food deprivation). (* - significant differences).

\begin{tabular}{|c|c|c|c|c|c|c|}
\hline Endpoint & $\begin{array}{l}\text { Regression } \\
\text { parameter }\end{array}$ & \multicolumn{2}{|c|}{$\begin{array}{c}\text { Parameter } \\
\text { value }\end{array}$} & $\mathbf{F}$ & df & $\mathrm{p}$ \\
\hline \multirow{4}{*}{ (1) Instar duration } & \multirow{2}{*}{ Slopes } & $\mathbf{J}_{3}$ & 0.229 & \multirow{2}{*}{0.365} & \multirow{2}{*}{1,655} & \multirow{2}{*}{0.545} \\
\hline & & $\mathbf{A}_{2}$ & 0.243 & & & \\
\hline & \multirow{2}{*}{ Intercepts * } & $\mathbf{J}_{3}$ & 1.653 & \multirow{2}{*}{3657.123} & \multirow{2}{*}{1,656} & \multirow{2}{*}{$<0.001$} \\
\hline & & $\mathbf{A}_{2}$ & 3.150 & & & \\
\hline \multirow{4}{*}{ (2) Body length } & \multirow{2}{*}{ Slopes } & $J_{3}$ & -0.063 & \multirow{2}{*}{0.014} & \multirow{2}{*}{1,490} & \multirow{2}{*}{0.904} \\
\hline & & $\mathbf{A}_{2}$ & -0.065 & & & \\
\hline & \multirow{2}{*}{ Intercepts * } & $\mathbf{J}_{3}$ & 2.111 & \multirow{2}{*}{1717.110} & \multirow{2}{*}{1,491} & \multirow{2}{*}{$<0.001$} \\
\hline & & $\mathbf{A}_{2}$ & 3.024 & & & \\
\hline
\end{tabular}




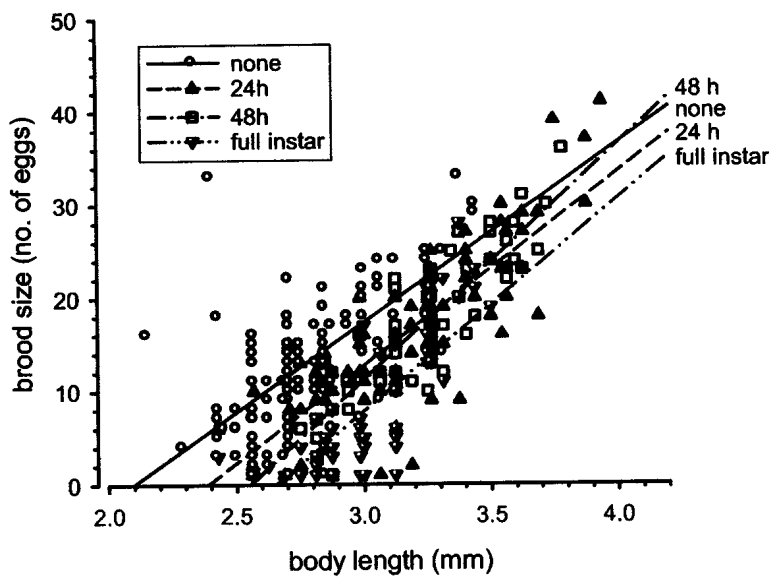

Fig. 9. Relationship between body length and brood size in instar $A_{3}$ individuals recovering from fixed periods of food deprivation in the previous instar $\left(\mathrm{A}_{2}\right)$ : none, $24 \mathrm{~h}, 48 \mathrm{~h}$, and full instar (see also Table II-B for further information on regression statistics).

an individual since there are several events synchronized and associated with instar duration (e.g. replacing the old carapace and egg release into the brood pouch). At constant temperature, two factors determined the duration of an instar: body length at the beginning of the instar and food availability during the instar. Under ad libitum food conditions an individual will take a minimal time (size-dependent) to moult (i.e. to build a new carapace and replace the old one). Similarly when food conditions deteriorate the individual takes longer to moult, with the maximum duration of the instar occurring in the complete absence of food.

The results fully support a common assumption of all models tested (Gurney et al. 1990, Hallam et al. 1990, Kooijman 1994): that allocation to metabolism (rule E) is derived directly from the stored reserves pool, since all individuals were capable of surviving one full instar without food. Moreover, these individuals were able both to produce a new carapace and to moult in the absence of food, thus supporting the assumption that moulting costs (rule F) are derived from stored reserves (Hallam et al. 1990, Kooijman 1994) rather than from assimilated mass as assumed by Gurney et al. (1990).

Growth ceases completely in the absence of food, supporting the idea that allocation to growth (rule C) occurs from assimilated mass (Gurney et al. 1990, Hallam et al. 1990) rather than from stored reserves (Kooijman 1994).
The results reported above indicate that reproductive investment is reduced under food deprivation. However, this reduction is not directly proportional to the duration food deprivation but is however more pronounced with increasing food deprivation. Most individuals deprived of food for $48 \mathrm{~h}$ failed to reproduce, although they received food for almost half of the instar, suggesting that allocation of mass to reproduction (rule D) is neither continuous nor irreversible (e.g. Bradley et al. 1991a, Bradley et al. 1991b, Gurney et al. 1990, Kooijman 1994) but is rather a more discrete event from a stored reserves pool, as suggested previously by Hallam et al. (1990). Continuous irreversible investment into eggs, which might compromise the chances of an adult surviving to release those eggs, could seriously jeopardize future fitness. Moreover, the mobilisation of reserve materials could be visually observed to occur only a few hours before moulting when the lipid droplets accumulated around the ovaries were displaced and ultimately aggregated to form eggs (pers. obs.).

The partitioning of resources (rule B) is adaptive rather than static since the effects of food deprivation are still visible in the recovery instar (Fig. 9). The decrease of fecundity is not confined to the instar where food deprivation occurs but extends to the next instar suggesting that the partitioning of resources is variable and dependent on food conditions. Thus, during recovery from food deprivation (rule $\mathrm{G}$ ), allocation to stored reserves associated with survival has higher priority than allocation to reproduction, which at least partly agrees with the model assumptions of Gurney et al. (1990).

Adaptive partitioning of accumulated resources should respond to the environmental conditions and internal physiological state of an individual, favouring growth in the juvenile instars and accumulation of storage in adult instars (Gurney et al. 1990). In the experiments described here, reproduction ceased before survival was compromised, supporting the hypothesis that a residual component of stored reserves is retained to ensure survival. Moreover, if we consider the resource costs involved at these two stages, juveniles are only concerned with growing, moulting, and surviving whilst adults must also provide substantial resources for reproduction. Moreover, juveniles should favour early maturation to maximise their fitness, while adults must also maximise their fecundity to achieve the same goal (Sibly \& Calow 1986).

None of the allocation models currently available for Daphnia is fully consistent with the experimental results obtained here (Table 4). Thus, a more general al- 


\begin{abstract}
Table 4. Validation of published allocation assumptions and allocation rules derived from this study (see text for further explanation).
\end{abstract}

\begin{tabular}{|c|c|c|c|c|c|}
\hline Regression parameter & \multicolumn{2}{|c|}{ Value } & $F$ & df & p \\
\hline \multirow{4}{*}{ Slope } & none & 19.21 & \multirow{4}{*}{1.646} & \multirow{4}{*}{3,347} & \multirow{4}{*}{0.178} \\
\hline & $24 \mathrm{~h}$ & 20.74 & & & \\
\hline & $48 \mathrm{~h}$ & 25.20 & & & \\
\hline & instar & 22.75 & & & \\
\hline \multirow{4}{*}{ Intercept * } & none & -40.28 & \multirow{4}{*}{53.916} & \multirow{4}{*}{3,348} & \multirow{4}{*}{$<0.001$} \\
\hline & $24 \mathrm{~h}$ & -49.51 & & & \\
\hline & $48 \mathrm{~h}$ & -64.39 & & & \\
\hline & instar & -60.42 & & & \\
\hline
\end{tabular}

Intercept comparisons (Tukey test)

location model, consistent with the observed phenomena, must be outlined, based on the following principles (Fig. 10, Table 4) :

1. allocation of mass to growth is derived directly from food

2. individuals will allocate proportionally less mass to reproduction under increasing food deprivation in the provisioning instar (e.g. instar $\mathrm{A}_{2}$ )

3. under starvation, individuals cease egg provisioning: they do not 'reproduce themselves to death';

4. combining points 2 and 3 suggests the existence of a common pool of stored reserves from which resources used for reproduction and survival can be obtained. However, a residual fraction of this common pool is not available for reproduction, but can be used to support survival costs (metabolism, activity and the formation of a new carapace) under starvation. The idea of residual stored reserves has already been advanced by one of the models (Gurney et al. 1990, McCauley et al. 1990), using the concept of 'weight-forlength' to address recovery from food deprivation. This concept assumes that « for each length there is a weight below which the individual would invest all resources in regaining weight without investing in reproduction ».

Assuming that the metabolic needs of an individual Daphnia have priority over other physiological processes, it is possible to establish a set of simple allocation rules governing the different processes. Allocation priorities can be treated separately in two ways (Fig. control

$24 h$

$48 \mathrm{~h}$

instar

9), considering the associated physiological processes:

(1) stored reserves $\geq$ growth, and (2) survival $>$ reproduction.

The rule (1) considers the situation where the individual is feeding and the partitioning of resources involves only stored reserves (to ensure survival) and growth. The rule (2) deals with the usage of stored reserves for survival and egg provisioning when moulting is due to occur.

The proposed allocation model subsumes all other models, and is biologically more realistic, since it does

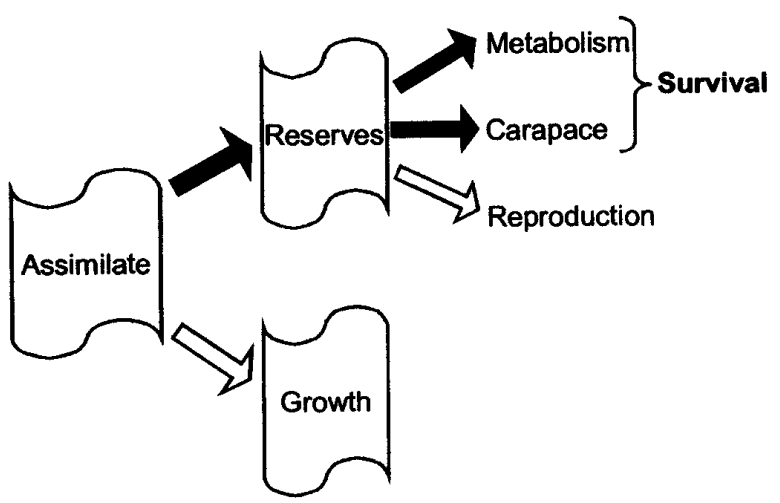

Fig. 10. Revised allocation model for an individual Daphnia (solid arrows - higher priority ; open arrows - lower priority). 
not imply abrupt shifts of allocation priorities at maturation. Moreover, its implementation in a future dynamic mass budget (DMB) model (Nogueira et al., in prep.) should be straightforward, since it can be based in a continuous adaptive function rather than in a set of equations for each physiological state as in existing models (Gurney et al. 1990, McCauley et al. 1990). Considering this allocation model for Daphnia, future work will be devoted to the development of a dynamic physiological model that can be used to describe the life history of an individual under stress conditions (food and toxic stress).

\section{Acknowledgements}

We acknowledge the EC for the financial support to conduct this study throughcu the STEP and Environment Programmes (contracts EV5V-CT91-0009 and EV5V-CT94-0422). This research was also supported by the «Fundação para a Ciência e Tecnologia» through the PRAXIS program and the British Council through a grant to António Nogueira. We are grateful to Fred Wrona and an anonymous reviewer for useful comments on an earlier version of this paper.

\section{References}

Allen Y., Calow P. \& Baird D.J. 1995. - A mechanistic model of contaminant-induced feeding inhibition in Daphnia magna. Environ. Toxicol. Chem., 14, 1625-1630.

Baird D.J., Barber I., Bradley M., Calow P. \& Soares A.M.V.M. 1989. - The Daphnia bioassay : a critique. Hydrobiologia, 188, 403-406.

Baird D.J., Barber I., Bradley M., Soares A.M.V.M. \& Calow P. 1991. - A comparative study of genotype sensitivity to acute toxic stress using clones of Daphnia magna Straus. Ecotox. Environ. Safe., 21, 257-265.

Banta A.M. \& Brown L.A. 1929. - Control of sex in Cladocera. I. Crowding the mothers as a means of controlling male production. Physiol. Zool., 2, 80-92

Berge W.F. 1978. - Breeding Daphnia magna. Hydrobiologia, 59, 121-123.

Bradley M.C., Baird D.J. \& Calow P. 1991a. - Mechanisms of energy allocation to reproduction in the cladoceran Daphnia magna Straus. Biol. J. Linn. Soc., 44, 325-333.

Bradley M.C., Perrin N. \& Calow P. 1991b. - Energy Allocation in the Cladoceran Daphnia Magna Straus, under Starvation and Refeeding. Oecologia, 86, 414-418.

Carvalho G.R. \& Hughes R.N. 1983. - The effect of food availability, female culture density and photoperiod on ephipia production in Daphnia magna Straus (Crustacea: Cladocera). Freshwat. Biol., 13, 37-46.

De Bernardi R. \& Peters R.H. 1987. - Why Daphnia ? Mem. Ist. Ital. Idrobiol., 45, 1-9.

Delaguerie P., Olivieri I. \& Gouyon P.H. 1993. - Environmental-Effects on Fitness-Sets Shape and Evolutionarily Stable Strategies. J. Theor. Biol., 163, 113-125.

Doma S. 1979. - Ephippia of Daphnia magna Straus - a technique for their mass production and quick revival. Hydrobiologia, 67, 183-188.

Enserink E.L., Kerkhofs M.J.J., Baltus C.A.M. \& Koeman J.H. 1995. - Influence of food quantity on maturation in Daphnia magna; evidence for a trade-off mechanism. Funct. Ecol., 9, 175185 .
Fernandez-Casalderrey A., Ferrando M.D. \& Andreu-Moliner E. 1994. - Effect of sublethal concentrations of pesticides on the feeding behavior of Daphnia magna. Ecotox. Environ. Safe., 27, 8289.

Glazier D.S. 1991. - Separating the respiration rates of embryos and brooding females of Daphnia magna : Implications for the cost of brooding and the allometry of metabolic rate. Limnol. Oceanogr., 36,354-362

Gulati R.D., Bodar C.W.M., Schuurmans A.L.G., Faber J.A.J. \& Zandee D.I. 1988. - Effects of cadmium exposure on feeding of freshwater planktonic crustaceans. Comp. Biochem. Phys. C, 90, 335-340.

Gurney W.S.C., McCauley E., Nisbet R.M. \& Murdoch W.W. 1990. - The Physiological ecology of Daphnia - a dynamic model of growth and reproduction. Ecology, 71, 716-732.

Hairston N.G. \& Bohonak A.J. 1998. - Copepod reproductive strategies: Life-history theory, phylogenetic pattern and invasion of inland waters. J. Marine. Syst., 15, 23-34.

Hallam T.G., Lassiter R.R., Li J. \& Suarez L.A. 1990. - Modelling individuals employing an integrated energy response: application to Daphnia. Ecology, 71, 938-954.

Hommen U., Poethke H.J., Dulmer U. \& Ratte H.T. 1993. - Simulation models to predict ecological risk of toxins in fresh-water systems. ICES J. Mar. Sci., 50, 337-347.

Kersting K. \& van der Honing H. 1981. - Effect of the herbicide dichlobenil on the feeding and filtering rate of Daphnia magna. (Sladecek V., ed.). Proc. Int. Assoc. Theor. Appl. Limnol./Trav. Assoc. Int. Limnol., 21,1135-1140.

Kooijman S.A.L.M. 1994. - Dynamic energy budgets in biological systems. Theory and applications in ecotoxicology, Cambridge University Press, Cambridge, UK.

Lampert W. 1977. - Studies on the carbon balance of Daphnia pulex De Geer as related to environmental conditions. II. The dependence of carbon assimilation on animal size, temperature, food concentration and diet species. Arch. Hydrobiol. Suppl., 48, 310335.

Lampert W. 1987. - Feeding and nutrition in Daphnia. Mem. Ist. Ital. Idrobiol., 45, 143-192.

McCauley E., Murdoch W.W. \& Nisbet R.M. 1990. - Growth, reproduction, and mortality of Daphnia pulex Leydig - Life at low food. Funct. Ecol. 4:505-514.

Peters R.H. \& De Bernardi R. 1987. - Daphnia. Mem. Ist. Ital. Idrobiol., v. 45, Consiglio Nazionale delle Richerche, Istituto Italiano di Idrobiologia, Verbania Palanza, Italy.

Porcella D.B., Rixford C.E. \& Slater J.V. 1969. - Molting and calcification in Daphnia magna. Physiol. Zool., 42,148-159.

Sibly R.M. \& Calow P. 1986. - Physiological ecology of animals, Blackwell Scientific Publications, Oxford, UK.

Slobodkin L.B. 1954. - Population dynamics in Daphnia obtusa Kurz. Ecol. Monogr., 24, 69-88.

SPSS. 1987. - SigmaStat 2.0 For Windows User's Manual.SPSS, Inc., Chicago.

Stearns S.C. 2000. - Life history evolution: successes, limitations, and prospects. Naturwissenschaften, 87, 476-486.

Stross R.G. \& Hill J.C. 1965. - Diapause induction in Daphnia requires two stimuli. Science, 150, 1462-1464.

Zaffagnini F. 1987. - Reproduction in Daphnia. Mem. Ist. Ital. Idrobiol., 45,245-284.

Zar J.H. 1998. - Biostatistical analysis, Prentice Hall Inc., Englewood Cliffs, New Jersey. 